Article

\title{
Tackling COVID-19 pandemic through research in Latin America and the Caribbean: A bibliometric analysis
}

\author{
Isabel Espinosa ${ }^{1}$, Victor Cuenca ${ }^{2}$, Ahmed Eissa-Garcés ${ }^{3}$ and Ivan Sisa ${ }^{4, *}$ \\ 1 School of Medicine, College of Health Sciences, Universidad San Francisco de Quito USFQ, Quito, Ecuador 1; \\ isaespi212@gmail.com \\ 2 School of Medicine, College of Health Sciences, Universidad San Francisco de Quito USFQ, Quito, Ecuador 2; \\ vdcuenca@estud.usfq.edu.ec \\ 3 School of Medicine, College of Health Sciences, Universidad San Francisco de Quito USFQ, Quito, Ecuador 3; \\ aeissag@estud.usfq.edu.ec \\ 4 School of Medicine, College of Health Sciences, Universidad San Francisco de Quito USFQ, Quito, Ecuador 4; \\ isisa@usfq.edu.ec \\ * Correspondence: isisa@usfq.edu.ec
}

\begin{abstract}
Latin America and the Caribbean (LAC) is one of the worst-hit regions globally by COVID-19 pandemic. Yet, scarce literature exists that examines the research strategy of LAC in facing COVID-19. The present study aims to quantify and assess the production of COVID-19 publications in thirty-two countries in LAC during the first half of 2020. A Scopus/PubMed/LILACS search was performed to retrieve research articles related to COVID-19 published from January 1 to July 31, 2020. Subgroup analysis including only original publications was used to better ascertain the contribution of LAC countries, and standardization measures were applied to comparisons of country-specific contributions. We identified 1291 publications across the region. Overall, most articles in the region were non-original (81.6\%), and the most productive countries were Brazil (43.9\%), Mexico (9.14\%), and Colombia (7.98\%). This trend shifted to Chile after the standardization. Among original studies, the most common study design was cross-sectional (25.8\%). LAC countries generate articles primarily pertaining to diagnosis and treatment $(27.4 \%)$. In the subgroup analysis, however, epidemiology and surveillance was the most prevalent research focus (24.1\%). LAC countries should perform more research with a higher level of evidence to inform health policy making to ease the burden of COVID-19 in the region.
\end{abstract}

Keywords: Health research policy; National health research system; COVID-19; Biomedical Research; Latin America and Caribbean.

\section{Introduction}

On the $11^{\text {th }}$ of March, 2020, the World Health Organization (WHO) declared the outbreak of the disease COVID-19, caused by infection with a newly discovered coronavirus, SARS-CoV2, a pandemic [1]. Since that time, the rapid spread of the virus has affected many regions, including Latin America and the Caribbean (LAC), where the current number of confirmed cases reportedly exceeds 6.5 million [2]. Brazil leads the region in the number of confirmed cases, followed by Peru, Mexico, and Colombia [2]. Peru, however, has the highest reported mortality rate, with an estimated total of 833 deaths per million as of August 23rd 2020 [3]. Although preventive strategies have been employed, urgent attention to the existing crisis is still required in LAC, where the outbreak of SARS-CoV-2 continues. Several research efforts have been carried out to gain a clearer understanding of COVID-19, notably, through the accelerated growth in scientific literature production [4]. For instance, articles related to this disease have 
been made freely available to the public online [5]. Additionally, the timeline to publication in academic journals has been reduced noticeably, with some articles reportedly undergoing a review and publication process of only one day [6]. However, it is essential that the emerging research focuses on quality over quantity for the advancement of medical practice on COVID-19. Bibliometric analysis allows a comprehensive evaluation of trends and progress in scientific production [7]. Thus, it can help researchers and policy makers to develop disease-specific public health initiatives [8]. Bibliometric papers focused on COVID-19 published to date have shown descriptive patterns of worldwide COVID-19 research output by mapping international collaboration in the field, evaluating the citation performance of different documents, and ascertaining the relative contribution of different research focuses to the total body of evidence [9-11]. Though these studies have been conducted mostly by Chinese affiliated authors, they have primarily focused on global results [12].

Currently, Latin America has become the new epicenter of the disease [13]. This region combined surpasses the number of deaths in the United States alone, with over 200,000 deaths being attributed to infection with the novel coronavirus [2]. Yet, despite the severity of the scenario, scarce literature exists that examines the research strategy of LAC in facing COVID-19. A comprehensive evaluation of the current research production is essential to inform regional and national health policies, current and future priorities in research, and planning of interventions that tackle COVID-19 in LAC. To address these necessities, we used a bibliometric analytic framework to analyze the progress of research on COVID-19 in thirty-two countries in LAC during the first half of 2020.

\section{Materials and Methods}

This is a cross-sectional study embedded in a bibliometric analysis. The research data was extracted from the PubMed, Scopus, and LILACS electronic databases. PubMed and Scopus have a high coverage of English-based journals, whereas LILACS includes local journals in LAC published mostly in Spanish and Portuguese.

\subsection{Search Strategy and selection criteria}

We applied the search strategy for two different time periods. The first time period ranged from January 1,2020 , to the $6^{\text {th }}$ of June, 2020. The second search was conducted to increase the sample size, and covered the time period ranging from June $5^{\text {th }}, 2020$, to July $31^{\text {st }}, 2020$. There were no restrictions in language. The keywords implemented in the search strategy used common Health Sciences Descriptors (DeCS in Spanish) to recover scientific output in LILACS, PubMed, and Scopus. We used the following search strategy in an iterative fashion for each of the 32 countries in LAC:

(((((()((((2019 novel coronavirus disease) OR COVID19) OR COVID-19 pandemic) OR SARSCoV-2 infection) OR COVID-19 virus disease) OR 2019 novel coronavirus infection) OR 2019$\mathrm{nCoV}$ infection) OR coronavirus disease 2019) OR coronavirus disease-19) OR 2019-nCoV disease) OR COVID-19 virus infection) AND Country [Affiliation])

The extracted data was imported into a Microsoft Excel worksheet. Before screening, we conducted a training session to standardize definitions. Screening by title and abstract was conducted independently by three members of the research team. Articles thought to be eligible during the first phase were then subject to full text screening. The inclusion criteria were as follows: (i) Articles related to health sciences and similar areas, (ii) Articles concerning COVID-19, (iii) Local data from a LAC country, with the exception of authors with local affiliations reporting data not from LAC, (iv) Publication date since January 2020, and (v) Article that provided all the required variables. 


\subsection{Data collection}

To guarantee consistency in the data collection the research team were trained to use standardized definitions across all study variables. Discrepancies were resolved by the lead author. Data including title, first and last author affiliation, country, language, month of publication, and journal were directly obtained from the manual screening. Bibliometric indicators included: (i) "Affiliation" for the first and last author, categorized as university, hospital, or other; (ii) "Publication type," categorized as original, systematic review, commentary/letter/editorial, or case/series report; (iii) "Design type" for original articles only, categorized as Ecological study, cross-sectional/prevalence/survey study, case-control study, cohort study, randomized control trial study, meta-analysis, or other; (iv) "Research focus" specific to COVID-19, categorized into epidemiology and surveillance system, biology research, early detection and prevention research, diagnosis and treatment research, provision of health services, psychosocial aspects, public policy, or other; and (v) "Journal Quartile", obtained manually from Scimago journal and country rank website, and categorized as Q1 (Quartile), Q2, Q3, Q4, or not applicable. Further, to fully associate a COVID-19 publication with a specific country, the authorship byline must not have included any author from outside LAC region; otherwise, this publication was categorized as a mixed contribution.

\subsection{Statistical analysis}

We used a descriptive analysis to summarize the baseline characteristics of the COVID-19 publications. Categorical variables were reported as counts and percentages. In our comparison of country-specific research production of original publications, we standardized the number of articles per 1 million individuals in the population, and per the number of reported deaths. COVID-19 deaths for the LAC countries were obtained from the WHO reports [14,15]. In addition, we performed a subgroup analysis including only original publications to better ascertain the specific contribution of LAC countries to the body of research. All analyses were conducted using R version 1.1.463.

\section{Results}

Our search strategy identified 3686 publications in total from the Scopus, PubMed, and LILACS databases between January 1 to July 31, 2020. After the screening process (Figure 1), 1122 duplicate articles were excluded, and an additional 1273 articles failed to fulfill the inclusion criteria. Overall, 1291 (35\%) studies were selected for the final review and statistical analysis. 


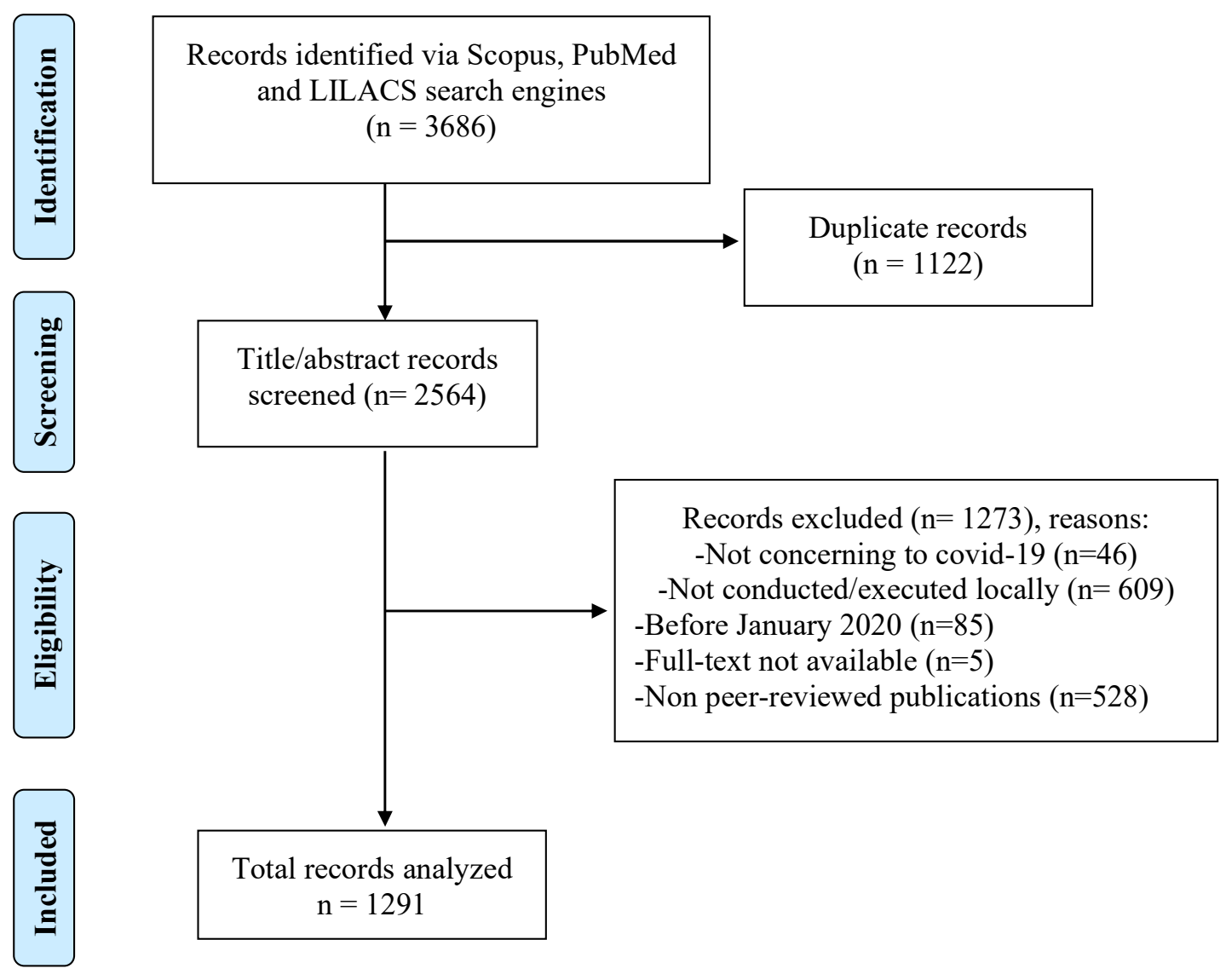

Figure 1. STROBE flowchart

\subsection{Characteristics of publications in Latin America and the Caribbean}

Table 1 shows that LAC countries produced more non original publications (81.7\%) than original studies (18.3\%). LAC researchers preferred to publish in English (79.7\%) than other languages. Among original studies that fell into one of the six defined categories, the most common were cross-sectional (25.8\%) reports. We found only 5 (2.1\%) randomized controlled trials (RCTs), and 16 (6.3\%) articles were classified as meta-analyses. It is worth mentioning that original studies that were categorized as "other" designs obtained the highest output in the region (53.8\%). These studies included several non-classical epidemiology designs, including genomic, mathematical modelling, and lab-based research papers. Regarding the scientific influence of the LAC publications, $40.6 \%$ of the studies were published in a Q1 journal. Travel Medicine and Infectious Disease journal published most of the contributions from the region (Table 2). Overall, academic institutions led the production of COVID-19 related publications in the region, with approximately $63 \%$ of the first and last author affiliations corresponding to a Universitybased institution (Table 1). 
Table 1. Baseline characteristics of Latin American and Caribbean publications related to covid-19

\begin{tabular}{|c|c|}
\hline Characteristic & $\begin{array}{c}\text { Total } \\
\mathrm{n}=1291\end{array}$ \\
\hline \multicolumn{2}{|l|}{ Publication type, n(\%) } \\
\hline Original & $236(18.3)$ \\
\hline Systematic review & $232(17.9)$ \\
\hline Commentary/Letter/Editorial & $770(59.6)$ \\
\hline Case/series report & $53(4.1)$ \\
\hline \multicolumn{2}{|l|}{ Language, $\mathrm{n}(\%)$} \\
\hline English & $1029(79.7)$ \\
\hline Spanish & $144(11.1)$ \\
\hline Portugues & $118(9.1)$ \\
\hline \multicolumn{2}{|l|}{ Study design, $\mathrm{n}(\%)^{\mathrm{a}}$} \\
\hline Ecologic & $19(8)$ \\
\hline Cross-sectional/Prevalence/Survey & $61(25.8)$ \\
\hline Case-control & $2(0.8)$ \\
\hline Cohort & $7(2.9)$ \\
\hline Randomized control trial & $5(2.1)$ \\
\hline Meta-analysis & $15(6.3)$ \\
\hline Otherb & $127(53.8)$ \\
\hline \multicolumn{2}{|l|}{ Journal quartile, n(\%) } \\
\hline Q1 & $524(40.6)$ \\
\hline Q2 & $350(27.1)$ \\
\hline Q3 & $220(17)$ \\
\hline Q4 & $103(7.9)$ \\
\hline Non ranked & $94(7.3)$ \\
\hline \multicolumn{2}{|l|}{ First author affiliation, $\mathrm{n}(\%)$} \\
\hline University & $808(62.6)$ \\
\hline Hospital & $172(13.3)$ \\
\hline Otherc & $311(24.1)$ \\
\hline \multicolumn{2}{|l|}{ Last author affiliation, $\mathrm{n}(\%)$} \\
\hline University & $719(63)$ \\
\hline Hospital & $150(13.1)$ \\
\hline Otherc & $272(21.1)$ \\
\hline
\end{tabular}

anly original studies $(\mathrm{n}=238)$

bIncludes genomic, mathematical modelling and lab research studies.

cOther category means affiliation to a research institute, ONG, or other institutions. Percentage may not sum to 100 because some publications have only one author 
Table 2. Top ten journals publishing LAC's articles regarding COVID- 19 related studies

\begin{tabular}{lcc}
\hline \multicolumn{1}{c}{ Journal } & Quartil & Number of articles \\
\hline Travel Medicine and Infectious Disease & 1 & 31 \\
Cadernos de Saúde Pública & 2 & 26 \\
Oral Diseases & 1 & 19 \\
Revista Colombiana de Cirugía & 4 & 19 \\
Science of the Total Environment & 1 & 18 \\
International Brazilian Journal of Urology & 2 & 16 \\
Journal of Medical Virology & 2 & 16 \\
Clinics & 3 & 15 \\
La Revista de la Sociedad Brasileña de Medicina Tropical & 3 & 14 \\
The American Journal of Tropical Medicine and Hygiene & 1 & 11 \\
\hline
\end{tabular}

Interestingly, a growing parallel between LAC scientific output and COVID-19 related mortality was observed (Figure 2). However, the scientific output decelerated during the month of July.

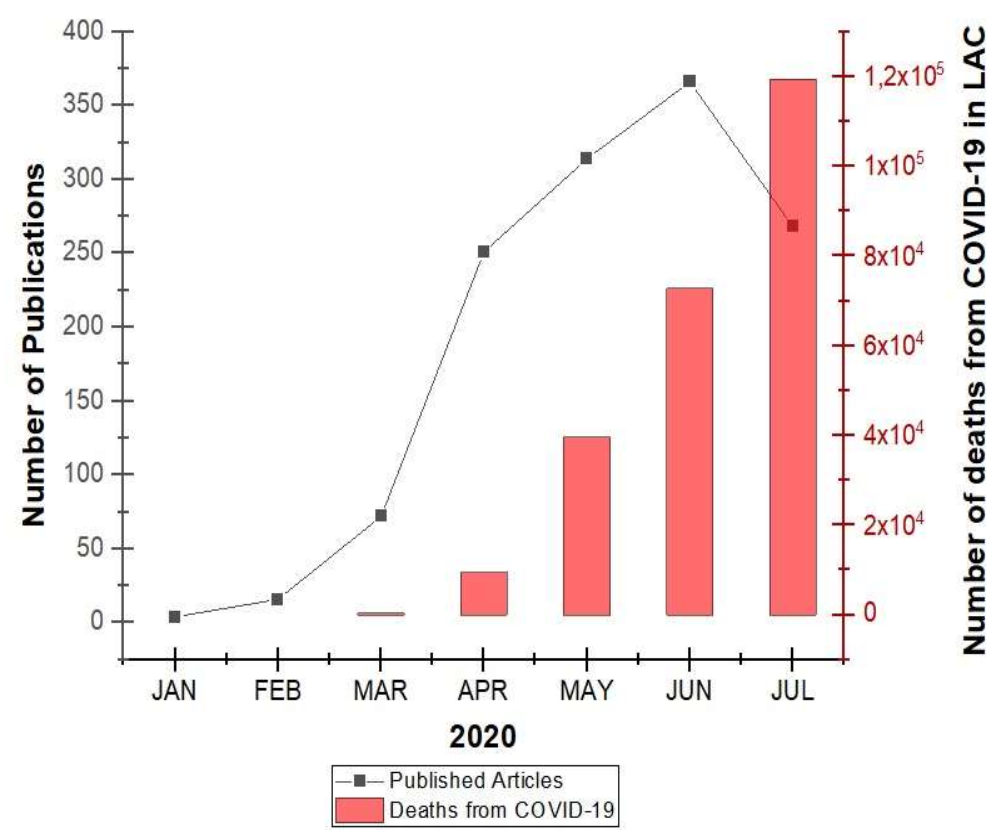

Figure 2. Monthly distribution of novel COVID-19 deaths and research output within Latin America and the Caribbean (LAC) 
Overall, the most productive individual countries in the region were Brazil (43.9\%; 567/1291), Mexico (9.14\%; 118/1291), and Colombia (7.98\%; 103/1291). Mixed collaboration was reported for 23.5\% (303/1291) of the articles. Countries located in Central America and the Caribbean were the lowest producers (Table $3)$.

Table 3. Distribution of Latin American and Caribbean publications by publication type $(n=1291)$

\begin{tabular}{|c|c|c|c|c|}
\hline Country & $\begin{array}{c}\text { Original } \\
n=236 \\
18.3 \% \\
\end{array}$ & $\begin{array}{c}\text { Systematic } \\
\text { review } \\
\mathrm{n}=232 \\
18 \% \\
\end{array}$ & $\begin{array}{c}\text { Commentary/Le } \\
\text { tter/Editorial } \\
n=770 \\
59.6 \% \\
\end{array}$ & $\begin{array}{c}\text { Case/Series } \\
\text { report } \\
n=53 \\
4.1 \% \\
\end{array}$ \\
\hline Barbados & - & - & $2(0.2)$ & - \\
\hline Trinidad and Tobago & - & - & $1(0.1)$ & $1(1.9)$ \\
\hline Argentina & $6(2.5)$ & $7(3)$ & $44(5.7)$ & $1(1.9)$ \\
\hline Brazil & $96(40.7)$ & $87(37.5)$ & $359(46.6)$ & $25(47.1)$ \\
\hline Chile & $11(4.7)$ & $12(5.2)$ & $32(4.1)$ & $2(3.8)$ \\
\hline Colombia & $13(5.5)$ & 27 (11.6) & $60(7.8)$ & $3(5.7)$ \\
\hline Cuba & - & - & $2(0.2)$ & - \\
\hline Costa Rica & - & - & $1(0.1)$ & - \\
\hline Dominican Republic & - & - & $2(0.2)$ & - \\
\hline Ecuador & $4(1.7)$ & $2(0.9)$ & $6(0.8)$ & $1(1.9)$ \\
\hline Grenada & - & $1(0.4)$ & - & - \\
\hline Jamaica & - & - & $1(0.1)$ & - \\
\hline Mexico & $29(12.2)$ & $20(8.6)$ & $59(7.7)$ & $10(18.8)$ \\
\hline Panama & - & $1(0.4)$ & $1(0.1)$ & - \\
\hline Peru & $4(1.7)$ & $5(2.1)$ & $24(3.1)$ & $3(5.7)$ \\
\hline Uruguay & - & $1(0.4)$ & $3(0.4)$ & - \\
\hline Venezuela & - & $1(0.4)$ & $3(0.4)$ & - \\
\hline Bolivia & $3(1.3)$ & $1(0.4)$ & $2(0.2)$ & - \\
\hline Guatemala & - & - & $2(0.2)$ & - \\
\hline Nicaragua & - & - & $1(0.1)$ & - \\
\hline Paraguay & - & $1(0.4)$ & $2(0.2)$ & - \\
\hline El Salvador & - & $2(0.9)$ & - & - \\
\hline Haiti & - & - & $1(0.1)$ & - \\
\hline Multiple collaboration & $70(29.7)$ & $64(27.6)$ & $162(21)$ & $7(13.2)$ \\
\hline
\end{tabular}

Data are presented as $\mathrm{n}(\%) ;(-)=$ missing data.

This trend persisted after the subgroup analysis assessing original contributions only. However, after standardizing research output by population and by number of reported deaths, the highest country producer was Chile (0.58 publications/per million adults and 102 publications/per 100,000 deaths), and 
the lowest was Peru (0.12 publications/per million adults and 15 publications/per 100,000 deaths) (Table $4)$.

Table 4. Standardized COVID-19 related publications in LAC by population and number of deaths

\begin{tabular}{lccccc}
\hline Country & $\begin{array}{c}\text { Number of } \\
\text { original } \\
\text { publications }\end{array}$ & Population $^{\text {a }}$ & $\begin{array}{c}\text { Articles per 1 } \\
\text { million population }\end{array}$ & $\begin{array}{l}\text { Cumulative } \\
\text { deaths }\end{array}$ & $\begin{array}{c}\text { Articles per } \\
\text { 100000 deaths }\end{array}$ \\
\hline Argentina & 6 & 45195774 & 0.13 & 6795 & 88 \\
Bolivia & 3 & 11673021 & 0.26 & 4366 & 69 \\
Brazil & 96 & 212559417 & 0.45 & 113358 & 85 \\
Chile & 11 & 19116201 & 0.58 & 10792 & 102 \\
Colombia & 13 & 50882891 & 0.26 & 16568 & 78 \\
Ecuador & 4 & 17643054 & 0.23 & 6277 & 64 \\
Mexico & 29 & 129132739 & 0.22 & 59610 & 49 \\
Peru & 4 & 32971854 & 0.12 & 27245 & 15 \\
\hline
\end{tabular}

aExtracted from: https://www.worldometers.info/population/latin-america-and-the-caribbean/

bExtracted from: https://www.who.int/docs/default-source/coronaviruse/situation-reports/20200824weekly-epi-update.pdf?sfvrsn=806986d1 2. Data update until August 23, 2020

\subsection{Primary research focus in Latin America and the Caribbean}

Table 5 shows that LAC countries generate articles primarily pertaining to diagnosis and treatment $(27.4 \%)$ and provision of health services (23.5\%). Early detection and prevention $(4.7 \%)$ research was the least common research focus among the publications. In the subgroup analysis of original contributions only, however, Epidemiology and surveillance (24.1\%) was the most common research focus followed by diagnosis and treatment (17.8\%), while the "other" category was the least common (3.4\%). Overall, Brazil produced the most articles related to diagnosis and treatment $(48 \%)$, followed by mixed collaborations (20.3\%) (Table 6). 
Table 5. Distribution of Latin American and Caribbean publications by specific research focus (n=1291)

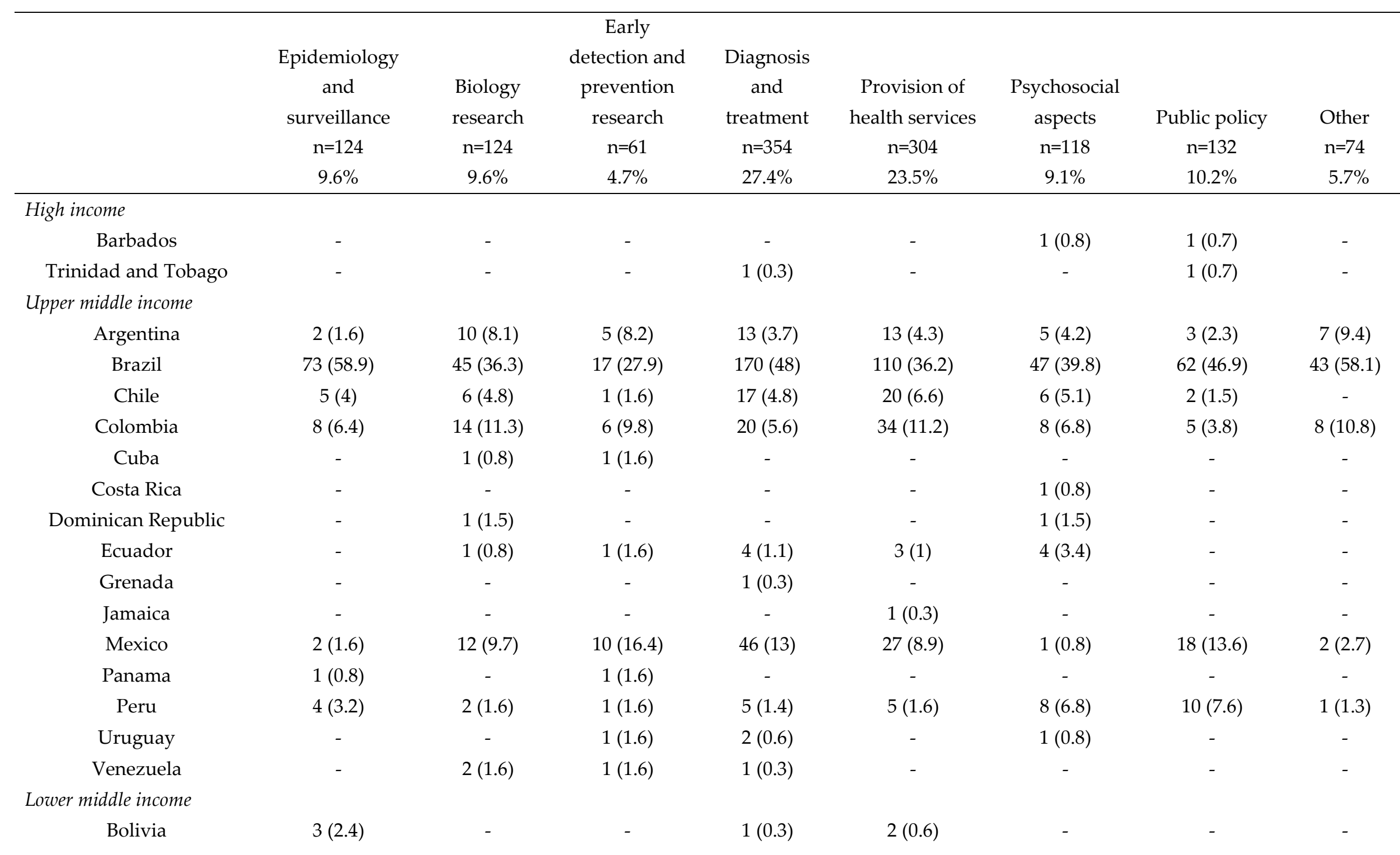




\begin{tabular}{|c|c|c|c|c|c|c|c|c|}
\hline Guatemala & - & - & - & - & $2(0.6)$ & - & - & - \\
\hline Nicaragua & - & - & - & - & - & - & $1(0.7)$ & - \\
\hline Paraguay & - & $1(0.8)$ & - & - & $1(0.3)$ & $1(0.8)$ & - & - \\
\hline El Salvador & - & $1(0.8)$ & - & $1(0.3)$ & - & - & - & - \\
\hline \multicolumn{9}{|l|}{ Lower Income } \\
\hline Haiti & - & - & - & - & - & $1(0.8)$ & - & - \\
\hline Multiple collaboration & $26(21)$ & $28(22.6)$ & $16(26.2)$ & $72(20.3)$ & $86(28.3)$ & $33(27.9)$ & $29(21.9)$ & $13(17.6)$ \\
\hline
\end{tabular}

Data are presented as n (\%). 
Table 6. Distribution of only original publications in Latin American and Caribbean countries by research focus ( $\mathrm{n}=236)$

\begin{tabular}{|c|c|c|c|c|c|c|c|c|}
\hline & $\begin{array}{c}\text { Epidemiology } \\
\text { and } \\
\text { surveillance } \\
\mathrm{n}=57 \\
24.1 \% \\
\end{array}$ & $\begin{array}{c}\text { Biology } \\
\text { research } \\
\mathrm{n}=29 \\
12.3 \% \\
\end{array}$ & $\begin{array}{c}\text { Early } \\
\text { detection and } \\
\text { prevention } \\
\text { research } \\
\mathrm{n}=15 \\
6.3 \% \\
\end{array}$ & $\begin{array}{c}\text { Diagnosis } \\
\text { and } \\
\text { treatment } \\
\mathrm{n}=42 \\
17.8 \% \\
\end{array}$ & $\begin{array}{c}\begin{array}{c}\text { Provision of } \\
\text { health services } \\
\mathrm{n}=38 \\
16.1 \%\end{array} \\
\end{array}$ & $\begin{array}{c}\text { Psychosocial } \\
\text { aspects } \\
\text { n=23, } \\
9.7 \% \\
\end{array}$ & $\begin{array}{c}\text { Public policy } \\
\mathrm{n}=24 \\
10.2 \% \\
\end{array}$ & $\begin{array}{c}\text { Other } \\
\mathrm{n}=8 \\
3.4 \%\end{array}$ \\
\hline \multicolumn{9}{|l|}{ High income } \\
\hline Barbados & - & - & - & - & - & - & - & - \\
\hline Trinidad and Tobago & - & - & - & - & - & - & - & - \\
\hline \multicolumn{9}{|l|}{ Upper middle income } \\
\hline Argentina & - & $1(3.4)$ & - & - & $1(2.6)$ & $4(17.4)$ & - & - \\
\hline Brazil & $32(56.1)$ & $12(41.4)$ & $5(33.3)$ & $15(35.7)$ & $12(31.6)$ & $8(34.8)$ & $10(41.7)$ & $2(25)$ \\
\hline Chile & $3(5.3)$ & - & $1(6.7)$ & $3(7.1)$ & $2(5.3)$ & $2(8.7)$ & - & - \\
\hline Colombia & $2(3.5)$ & $1(3.4)$ & - & $2(4.8)$ & $4(10.5)$ & $2(8.7)$ & $2(8.3)$ & - \\
\hline Cuba & - & - & - & - & - & - & - & - \\
\hline Costa Rica & - & - & - & - & - & - & - & - \\
\hline Dominican Republic & - & - & - & - & - & - & - & - \\
\hline Ecuador & $1(1.7)$ & $1(3.4)$ & - & $1(2.4)$ & - & - & - & $1(12.5)$ \\
\hline Grenada & - & - & - & - & - & - & - & - \\
\hline Jamaica & - & - & - & - & - & - & - & - \\
\hline Mexico & $2(3.5)$ & $6(20.7)$ & $4(26.7)$ & $7(16.7)$ & $3(7.9)$ & $1(4.3)$ & $4(16.7)$ & $2(25)$ \\
\hline Panama & - & - & - & - & - & - & - & - \\
\hline Peru & $2(3.5)$ & - & - & - & - & $1(4.3)$ & $1(4.2)$ & - \\
\hline Uruguay & - & - & - & - & - & - & - & - \\
\hline Venezuela & - & - & - & - & - & - & - & - \\
\hline \multicolumn{9}{|l|}{ Lower middle income } \\
\hline Bolivia & $3(5.3)$ & - & - & - & - & - & - & - \\
\hline
\end{tabular}




$\begin{array}{cccccccc}\text { Guatemala } & - & - & - & - & - & - & - \\ \text { Nicaragua } & - & - & - & - & - & - & - \\ \text { Paraguay } & - & - & - & - & - & - \\ \text { El Salvador } & - & - & - & - & - & - \\ \text { Lower Income } & - & - & - & - & - \\ \text { Haiti } & 12(21) & 8(27.6) & 5(33.3) & 14(33.3) & 16(42.1) & 5(21.7) & 7(29.2) \\ \text { Multiple collaboration } & & & & & 3(37.5)\end{array}$

Data are presented as n (\%). 


\subsection{Original publications: overall trend, country-specific contribution, and impact}

Table 7 shows that most original articles were published in Q1 journals (47.5\%), with the majority of these articles being classified as mixed collaborations (39.4\%). Brazil was the main producer of Q1 publications (34.8\%) across the region, but also had the largest number of publications in nonranked journals (66.7\%).

Table 7. Distribution of only original Latin American and Caribbean publications by SCImago journal ranking system $(\mathrm{N}=236)$

\begin{tabular}{|c|c|c|c|c|c|}
\hline Country & $\begin{array}{c}Q 1 \\
n=112 \\
47.5 \%\end{array}$ & $\begin{array}{l}\text { Q2 } \\
n=69 \\
29.2 \%\end{array}$ & $\begin{array}{c}\text { Q3 } \\
n=16 \\
6.8 \%\end{array}$ & $\begin{array}{c}\mathrm{Q} 4 \\
\mathrm{n}=15 \\
6.4 \%\end{array}$ & $\begin{array}{c}\text { Non-ranked } \\
\mathrm{n}=24 \\
10.2 \%\end{array}$ \\
\hline Barbados & - & - & - & - & - \\
\hline Trinidad and Tobago & - & - & - & - & - \\
\hline Argentina & $2(1.8)$ & $4(5.8)$ & - & - & - \\
\hline Brazil & $39(34.8)$ & $36(52.2)$ & $5(31.2)$ & - & $16(66.7)$ \\
\hline Chile & $5(4.5)$ & $3(4.3)$ & - & $3(20)$ & - \\
\hline Colombia & $3(2.7)$ & $3(4.3)$ & - & $5(33.3)$ & $2(8.3)$ \\
\hline Cuba & - & - & - & - & - \\
\hline Costa Rica & - & - & - & - & - \\
\hline Dominican Republic & - & - & - & - & - \\
\hline Ecuador & $4(3.6)$ & - & - & - & - \\
\hline Grenada & - & - & - & - & - \\
\hline Jamaica & - & - & - & - & \\
\hline Mexico & $13(11.6)$ & $10(14.5)$ & $3(18.7)$ & $1(6.7)$ & $2(8.3)$ \\
\hline Panama & - & - & - & - & - \\
\hline Peru & $1(0.9)$ & $1(1.4)$ & $1(6.2)$ & - & $1(4.2)$ \\
\hline Uruguay & - & - & - & - & - \\
\hline Venezuela & - & - & - & - & - \\
\hline Bolivia & $1(0.9)$ & - & $2(12.5)$ & - & - \\
\hline Guatemala & - & - & - & - & - \\
\hline Nicaragua & - & - & - & - & - \\
\hline Paraguay & - & - & - & - & - \\
\hline El Salvador & - & - & - & - & - \\
\hline Haiti & - & - & - & - & - \\
\hline Multiple collaboration & $44(39.3)$ & $12(17.4)$ & $5((31.2)$ & $6(40)$ & $3(12.5)$ \\
\hline
\end{tabular}

Data are presented as $\mathrm{n}(\%) ;(-)=$ missing data.

Figure 3 shows that among original publications, the most prevalent study design was the category of "other" (53.8\%), and the least common design was case-control (0.8\%). Mixed collaboration produced more meta-analysis and cross-sectional publications compared to Brazil 


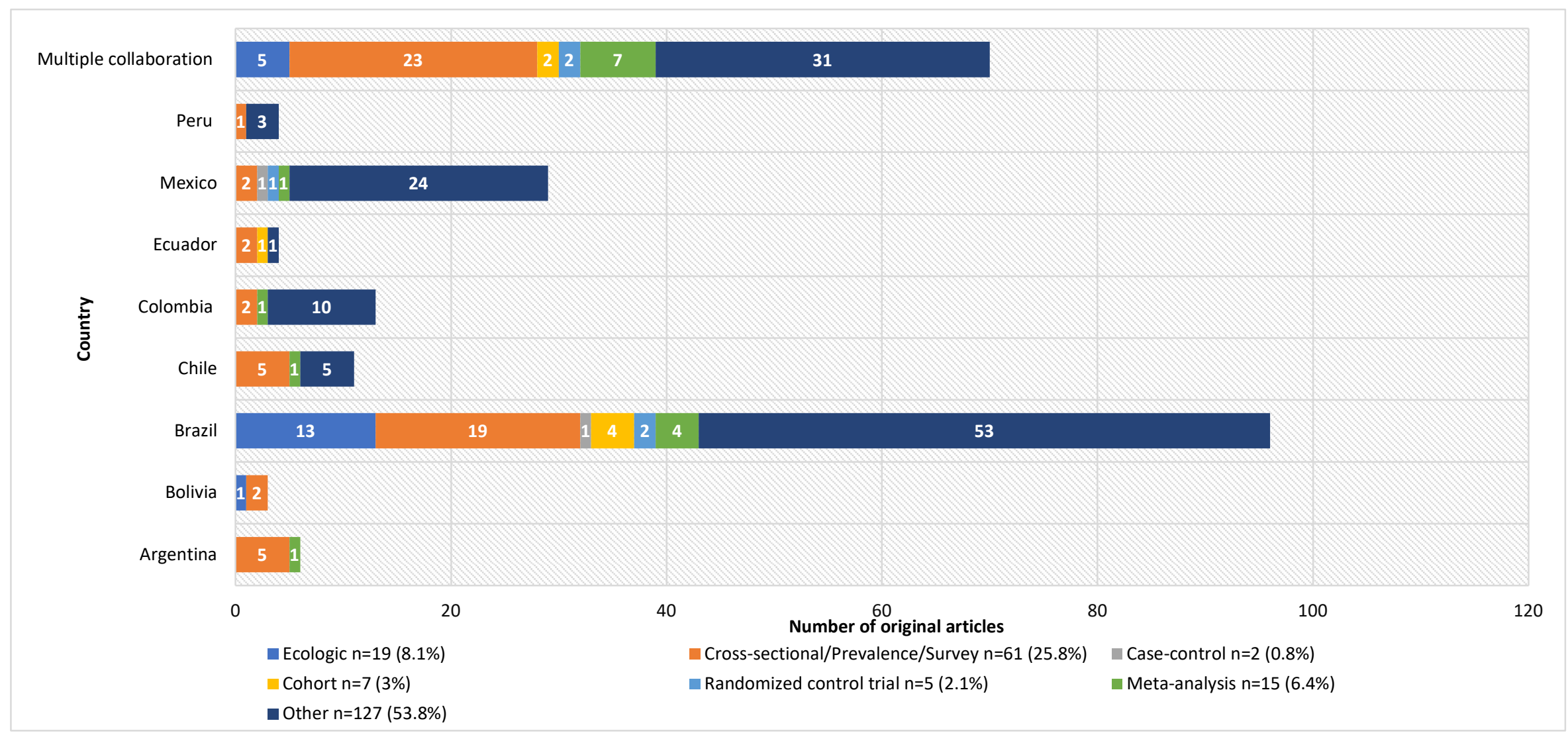

Figure 3. Distribution of study designs on original articles

The bars represent distribution of study designs (ecologic, cross-sectional/prevalence/survey, case-control, cohort, randomized control trial, meta-analysis, other) among only original studies in Latin America \& the Caribbean region. Study design others includes genomic, mathematical modelling and lab research studies. The numbers correspond to each number of articles found within that category 
Below, each research focus contribution from LAC is summarized:

- Epidemiology and surveillance-24.1\%

Epidemiological research in the region was mostly dedicated to reporting the burden of COVID-19 (prevalence and incidence), and addressing under-reporting in different geographical areas, primarily Brazil. Some papers reported modelling data and the impact of risk mitigation interventions at the population level. Risk factors such as other viral diseases (e.g. Dengue) and determinants of health that predispose the development of COVID-19 were reported as well. Few studies were dedicated to reporting the effective reproductive number in the region, and how it varies according to the implementation of multifaceted public health interventions.

- Diagnosis and treatment-17.8\%

Published literature in this category focused on reporting the most common underlying conditions, clinical symptoms, and laboratory/imaging findings among patients treated for COVID-19, as well as admissions criteria for Intensive Care Units. Some studies investigated potential predictive tools to identify disease severity and lethality in patients. Other imaging focused studies evaluated the utility of chest x-ray in the early diagnosis of COVID-19. Treatment options that were assessed in published research included a variety of drugs such as glucocorticoids, convalescent plasma, lithium, famotidine, and sofosbuvir. We found five randomized clinical trials (RCTs) conducted in the region, which evaluated the following drugs: chloroquine diphosphate, ACEI/ARB, remdesivir, and hydroxychloroquine alone or in combination with azithromycin or nitazoxanide.

- Provision of health services $-16.1 \%$

In overall, in this category, the published evidence provided recommendations on safety measures for health care workers and their associated facilities, especially among surgeons and oncologists. The biosecurity measures required to return to elective procedures and disease management and treatment options for cancer patients were emphasized. Additionally, diabetes and ethics topics were discussed in terms of impact and health provision, respectively.

- Biology research $-12.3 \%$

Biological research in the region focused on three main topics. First, the phylogeographic characteristics of the virus and is relationship to known strains of coronavirus were examined. For example, several studies undertook phylogeographic reconstruction of SARS-CoV-2 and found a relationship with the bat SARS-like coronavirus. Two other studies focused on the tendency for genome sequences in South America to be analogous to European strains rather than Chinese, indicating positive selection and mutations taking course. Second, the pathophysiology of the virus was investigated, and researchers reported a relationship between ACE2 receptor and symptom severity among patients with COVID-19. Investigations of different pathways for other symptoms like anosmia, hypoxemia, coagulation, and interstitial pneumonitis were also reported. Third, various studies focused on molecular investigations aimed at targeted therapeutic approaches.

- Public policy $-10.2 \%$

Studies related to public policy in the region were mainly dedicated to evaluating the impact of partial lockdown and social isolation/distancing. Some of these studies combined epidemiology and surveillance data to model the application of public policies in LAC.

- Psychosocial aspects $-9.7 \%$

Studies aimed to address psychosocial issues specific to COVID-19, such as suicide during quarantine; perception of stress during the pandemic; emotional impact of the pandemic on 
caregivers; anxiety in scheduling medical appointments; and how variance in personality may require tailored prevention strategies to cope with quarantine. Another important component that has been evaluated is the social impact of COVID-19including changes in lifestyle, eating habits, and physical activity that have occurred due to confinement. Finally, some publications reported on the implications of distanced medical education.

- Early detection and prevention research $-6.3 \%$

Most of the studies in this category mathematically modeled the impact of social distancing measures and the inefficiency of implementing "soft" quarantine measures. Some studies reported evidence regarding personal protection measures at the community and in health care facilities. At the community level, one study assessed the impact of hand washing as a containment measure within a complicated community. At the health care facility level, another study reported on the use of plasma hydrogen peroxide for intrahospital disinfection.

- Other $-3.4 \%$

This category encompasses studies regarding environmental issues, media, and dietary habits during the lockdown. For example, one study analyzed the ozone levels and air quality during partial lockdown in Brazil. Other studies have investigated potential media misinformation, exaggeration, and excess fear generated in relation to the COVID-19 pandemic.

\section{Discussion}

During this unprecedented pandemic, opportunities to research COVID-19 and its various impacts have soared. Though LAC is not globally distinguished by a high research production, it has put efforts in place to tackle the pandemic, some of which are still in progress. Information is the first line of defense to confront a pandemic and can only be obtained through research. The present study sought to quantify and assess the LAC scientific literature output specific to the COVID-19 crisis. Our primary findings are: (i) Production of COVID-19 related publications decelerated in the region during the last month of the semester, (ii) Most articles in the region were non-original (81.6\%), (iii) Among original articles, there was a lack of interventional studies, and (iv) Epidemiology/surveillance was the main research focus $(24.1 \%)$.

Our results advance the current understanding of the production of COVID-19 related publications among LAC countries in several ways. First, we expanded upon previous bibliometric studies conducted in the region, which presented data until April and only included countries of Latin America [16,17]. The present study provides data until July and encompasses Caribbean countries in the search as well. Second, we performed a subgroup analysis evaluating only original articles to better quantify and ascertain the LAC contribution of COVID-19 related publications. Thus, we were able to provide several bibliometric indicators of the impact of these publications, whereas previous bibliometric research on COVID-19 related publications in the region primarily reported on production variables [16]. One analysis using several databases classified publications into general topics including meta-analysis, general aspects, and epidemiological topics. In contrast, our analysis provides a detailed overview of the LAC COVID-19 publications by categorizing by study design and by eight different research focuses. Hence, we included areas not covered in this previous publication, such as provision of health services and public policy aspects [17]. 
The fact that scientific output in LAC has decelerated during the month of July is alarming, considering the fact that COVID-19 related mortality continues to rise in the region. This may be related to economic repercussions of the pandemic, especially in circumstances where research budgets have been cut in order to supplement institutions that have been providing aid during the crisis [18]. To maintain a consistent flow of scientific output, LAC must once again adapt to perform research efficiently with limited resources. The countries with the greatest number of deaths by SARS-CoV2 in the study region are Brazil, Mexico, Peru, Colombia, and Chile [15]. Governmental policies to aid research have been employed in all the aforementioned countries. Brazil, for example, has allocated more than 100 million dollars to research focused on diagnosis and prevention of SARS-CoV2 infection [19]. However, investment does not necessarily translate to a direct increase in scientific output to confront COVID-19. Governments in LAC have displayed a lack of awareness by not recognizing the importance of the generation of knowledge, which ultimately benefits all members of society [18]. The current crisis is an important opportunity for regional stakeholders to support appropriate public health decisions and initiatives that lead to a prompt recovery for the region as a whole [20].

It is important to note that a high output of scientific literature does not necessarily mean that a country is producing quality research; thus, other factors need to be assessed [21]. In our study, most articles (40.6\%) were published in a Q1 journal, which is associated with a higher quality and impact. This percentage rose up to $47.4 \%$ when original publications were assessed alone. Another bibliometric analysis found that Latin American publications regarding COVID-19 were published mostly in Q2 and Q3 journals [16]. A possible reason for this finding could be that this analysis used a search strategy that retrieved research published only until the $23^{\text {rd }}$ of April; thus, identifying a smaller sample compared to our study. Overall, LAC researchers preferred to publish in Travel Medicine Infectious Disease journal as described elsewhere [16]. However, another bibliometric analysis found that Cadernos de Saúde Pública was the most prevalent journal [22], which is not surprising, considering that Brazil is the main producer of the region.

Articles involving international collaboration are more likely to be published in a Q1 journal, which exemplifies the idea that collaborative research between developed and developing countries brings together the necessary skills and brainpower to maximize research efforts [23,24]. Overall, in the region, there are more non-original articles (81.6\%) than original articles $(18.3 \%)$. From the non-original, 59.6\% articles are a commentary/letter/editorials communication. This reflects the rapid increase in scientific output at the beginning of the pandemic. One reason for this spike in non-original articles could be that journals instituted a fast track for revisions of COVID-19 related articles, with a median time of acceptance of 2-6 days [6]. Another reason why most research output from LAC at that time was non-original may be that at the beginning of the pandemic, most of the disease burden fell in China and European countries (Spain and Italy). Thus, LAC countries were in the midst of preparing their healthcare systems to receive imported cases. Therefore, most of the LAC COVID-19 related publications during the first trimester of 2020 reflected personal opinions of how containment efforts should be taken at a local, national, and regional level. In our study, observational studies led the publication pattern in the region. Experiences such as Ebola in 2014, indicates that research is more inclined to transversal rather than longitudinal patterns. This may be explained by the fact that health emergencies are alleviated faster with shortterm benefit, rather than over the course of long-term observation [25]. However, the SARS-CoV-2 
virus seems to behave differently compared to the previous viruses such as MERS and SARS-CoV-1 [26]. In 2003, the SARS epidemic was able to be contained because most patients were symptomatic, and the transmission from person to person was not as efficient as in the case of the SARS-CoV-2 virus [27]. Thus, COVID-19 continues to be a threat that requires both current and long-term attention. Currently, in the LAC region, the production of studies with higher level of evidence that are sufficient to inform health policymaking, such as cohorts (2.9\%), RCTs (2.1\%), and meta-analysis $(6.3 \%)$ studies are limited. Unfortunately, this is not the first time that LAC has struggled with clinical research, despite a good enrollment capability [28]. One of the main reasons for that could be the lack of a proper research agenda and scarce funding [19,29].

Among LAC countries, the overall production of COVID-19 related publications focused in the area of diagnosis/treatment (27.4\%), which is in accordance with previous bibliometric studies conducted of the region [16,17]. However, our subgroup analysis examining only original articles demonstrated that the main area of research focus in the region was actually

epidemiology/surveillance (24.1\%). As the pandemic continues, other areas such as early detection and prevention research, diagnosis and treatment, and provision of health services should become a priority to more directly inform efforts to alleviate the crisis in the region [20].

Our study has several strengths, the first of which is the comprehensive quantification and mapping of the research output conducted in LAC, which is a well-defined worldwide epicenter of COVID-19. Our study also included the LILACS dataset, which is a regional research engine that encompasses publications not indexed in PubMed or Scopus. Therefore, underreporting of LAC COVID-19 related publications may be less likely. Despite these strengths, some limitations should be mentioned. First, publications before January 2020 have not been included in this study. However, the first COVID-19 case was reported to reach LAC in February of 2020, so the potential of misclassification is low. Second, bibliometric indicators regarding impact such as the $\mathrm{H}$ index have not been evaluated. However, we utilized journal quartiles and specific research focuses to assess the impact of LAC contributions. Third, we only included first and last author affiliations in the analysis, which may lead to an underrepresentation of LAC authors who are listed other authorship positions. Future studies should evaluate all authorship bylines, and their affiliations. Our study has important implications for regional decision making that can strengthen public policies and aid the scientific community in LAC. The shortage of original articles in the region and the deceleration in the COVID-19 scientific output should capture the attention of regional and local leaders and stakeholders. The pandemic can be reframed as an opportunity to increase the volume of research produces according to high quality standards. Given the large burden of COVID-19 cases that LAC carries, this region is likely eligible for clinical studies that may provide a better understanding of the disease and its course [28,29]. Local governments should encourage research efforts through proper allocation of funding and by facilitating international/regional collaboration. Though the pandemic seems likely to continue in the long-term, no pharmacologic treatment or vaccine is currently available. Thus, in addition to increasing research efforts in the area of diagnosis and treatment, LAC countries should perform more research in areas such as early detection and prevention, provision of health services, and evaluation of national programs implemented. While most regional governments expect developed countries to look for long-term solutions to the COVID-19 crisis, LAC countries may have access to opportunities and initiatives that could contribute vital knowledge that would be valuable at a regional and global level. 


\section{Conclusions}

In conclusion, COVID-19 continues to be an international threat and requires immediate research attention, especially in epicenter areas, such as LAC countries. Researchers in this region have demonstrated a great interest in spreading information internationally through high impact journals. However, non-original articles are dominant in the region, and among the original contributions, interventional studies are scarce. Researchers and policy makers in LAC must adopt the mindset that in times of emergency and uncertainty, high quality information is the best defense we have to prepare the world for this pandemic and others to come.

Author Contributions: Conceptualization, I.S; methodology, I.S.; formal analysis, I.S., I.E., V.C. and A.E.G.; investigation, I.E., V.C. and A.E.G.; data curation, I.E., V.C. and A.E.G; writing-original draft preparation, I.E.; writing-review and editing, I.S., V.C. and A.E.G.; supervision, I.S. All authors have read and agreed to the published version of the manuscript.

Funding: This research received no external funding.

Acknowledgments: The authors thank Mikala Osani for assistance in language editing.

Conflicts of Interest: The authors declare no conflict of interest.

\section{References}

1. Cucinotta D, Vanelli M. WHO declares COVID-19 a pandemic. Acta Biomed, 2020,91,157-160. doi:10.23750/abm.v91i1.9397

2. World Health Organization. WHO Coronavirus Disease (COVID-19) dashboard. Available from: https://covid19.who.int/. Accessed 2020 July 26.

3. University of Oxford. Our world in data. Available from: https://ourworldindata.org/grapher/totalcovid-deaths-per-million. Accessed 2020 July 26.

4. Brainard J. Scientists are drowning in COVID-19 papers. Can new tools keep them afloat? Available from: https://www.sciencemag.org/news/2020/05/scientists-are-drowning-covid-19-papers-can-newtools-keep-them-afloat. Accessed 2020 July 26.

5. Viglione G. How scientific conferences will survive the coronavirus shock. Nature 2020,582,166-167. doi:10.1038/d41586-020-01521-3

6. Kun Á. Time to acceptance of 3 days for papers about COVID-19. Publications 2020,8,30. doi:10.3390/publications8020030

7. Durieux V, Gevenois PA. Bibliometric indicators: quality measurements of scientific publication. Radiology 2010,255,342-351. doi:10.1148/radiol.09090626

8. Ortiz AP, Calo WA, Suárez-Balseiro C, Maura-Sardo M, Suárez E. Bibliometric assessment of cancer research in Puerto Rico, 1903-2005. Rev Panam Salud Publica 2009,25,353-361. doi:10.1590/s102049892009000400010

9. Lou J, Tian SJ, Niu SM, Kang X, Lian H, Zhang L, et al. Coronavirus disease 2019: a bibliometric analysis and review. Eur Rev Med Pharmacol Sci 2020,24,3411-3421. doi:10.26355/eurrev_202003_20712

10. Chahrour M, Assi S, Bejjani M, Nasrallah AA, Salhab H, Fares M, et al. A Bibliometric analysis of COVID-19 research activity: a call for increased output. Cureus 2020,12,e7357. doi:10.7759/cureus.7357

11. Hamidah I, Sriyono, Hudha MN. A Bibliometric analysis of covid-19 research using VOSviewer. Indonesian Journal of Science and Technology 2020,5,209-216. 
12. Fan J, Gao Y, Zhao N, Dai R, Zhang H, Freg X, et al. Bibliometric analysis on COVID-19: a comparison of research between English and Chinese studies. Front Public Health 2020,8. doi:10.3389/fpubh.2020.00477

13. NPR. Latin America becomes a new epicenter of the coronavirus pandemic. Available from: https://www.npr.org/2020/06/03/869053446/latin-america-becomes-a-new-epicenter-of-thecoronavirus-pandemic. Accessed 2020 July 26.

14. World Health Organization. Coronavirus disease (COVID-19) weekly epidemiological update and weekly operational update. Available from: https://www.who.int/emergencies/diseases/novelcoronavirus-2019/situation-reports/. Accessed 2020 August 23.

15. Statista. COVID-19 in Latin America \& Caribbean: deaths by country. Available from: https://www.statista.com/statistics/1103965/latin-america-caribbean-coronavirus-deaths/. Accessed 2020 July 26.

16. Gregorio-Chaviano O, Limaymanta CH, López-Mesa EK. Análisis bibliométrico de la producción científica latinoamericana sobre COVID-19. Biomedica 2020,40,(Supl. 2). doi:10.7705/biomedica.5571

17. Fiesco-Sepúlveda KY, Serrano-Bermúdez LM. Contributions of Latin American researchers in the understanding of the novel coronavirus outbreak: a literature review. PeerJ 2020,8,e9332. doi:10.7717/peerj.9332

18. Pérez Ortega R, Wessel L. 'We're losing an entire generation of scientists.' COVID-19's economic toll hits Latin America hard. Available from: https://www.sciencemag.org/news/2020/08/we-re-losingentire-generation-scientists-covid-19-s-economic-toll-hits-latin-america. Accessed 2020 August 24.

19. Rueda A. Pese a crisis, Latinoamérica financia investigación en COVID-19. Available from: https://www.scidev.net/america-latina/coronavirus/noticias/pese-a-crisis-latinoamerica-financiainvestigacion-en-covid-19.html. Accessed 2020 July 26.

20. Greer SL, King EJ, da Fonseca EM, Peralta-Santos A. The comparative politics of COVID-19: The need to understand government responses. Global Public Health 2020,15,1413-1416. doi:10.1080/17441692.2020.1783340

21. Liu W, Hu G, Gu M. The probability of publishing in first-quartile journals. Scientometrics 2016,106,1273-1276. doi:10.1007/s11192-015-1821-1

22. Gallegos M, Cervigni M, Consoli AJ, Caycho-Rodríguez, Polanco FA, Martino P, et al. COVID-19 in Latin America: a bibliometric analysis of scientific publications in health. Electron J Gen Med 2020,17,em261. doi:10.29333/ejgm/8460

23. Didegah F, Thelwall M. Which factors help authors produce the highest impact research? Collaboration, journal and document properties. Journal of Informetrics 2013,7,861-873. doi:10.1016/j.joi.2013.08.006

24. Rahman MM, Ghoshal UC, Ragunath K, Jenkins G, Rahman M, Edwards C, et al. Biomedical research in developing countries: Opportunities, methods, and challenges. Indian J Gastroenterol 2020. doi:10.1007/s12664-020-01056-5

25. National Academies of Sciences, Engineering, and Medicine, Health and Medicine Division, Board on Health Sciences Policy, Board on Global Health, Committee on Clinical Trials During the 2014-2015 Ebola Outbreak. Integrating Clinical Research into Epidemic Response: The Ebola Experience. (Busta ER, Mancher M, Cuff PA, McAdam K, Keusch G, eds.). Washington (DC): National Academies Press (US); 2017. doi:10.17226/24739 
26. Rabaan AA, Al-Ahmed SH, Bazzi AM, Al-Tawfiq JA. Dynamics of scientific publications on the MERSCoV outbreaks in Saudi Arabia. J Infect Public Health 2017,10,702-710. doi:10.1016/j.jiph.2017.05.005

27. Yale School of Medicine. COVID-19 is here. Now how long will It Last? Available from: https://medicine.yale.edu/news-article/23446/. Accessed 2020 August 23.

28. Malamud C, Núñez R. El COVID-19 en América Latina: desafíos políticos, retos para los sistemas sanitarios e incertidumbre económica - Elcano. Available from:

http://www.realinstitutoelcano.org/wps/portal/rielcano_es/contenido?WCM_GLOBAL_CONTEXT=/e lcano/elcano_es/zonas_es/ari27-2020-malamud-nunez-covid-19-en-america-latina-desafios-politicosretos-sistemas-sanitarios-e+incertidumbre-economica. Accessed 2020 August 23.

29. Coronel E, Halstead D, Fregni F. Clinical research in Latin America: obstacles and opportunities. Clin Investig (Lond) 2011,1,911-913. doi:10.4155/cli.11.83 